\title{
Label-Free Vapor Selectivity in Poly(p-Phenylene Oxide) Photonic Crystal Sensors
}

\author{
Paola Lova, ${ }^{* \dagger}+$ Chiara Bastianini, ${ }^{\ddagger}$ Paolo Giusto, ${ }^{\ddagger}$ Maddalena Patrini, ${ }^{\S}$ Paola Rizzo, " Gaetano Guerra, \\ Mario Iodice, ${ }^{\perp}$ Cesare Soci, $^{\#}$ and Davide Comoretto ${ }^{*}{ }^{\ddagger}$ \\ ${ }^{\dagger}$ Energy Research Institute at NTU (ERI@AN), Interdisciplinary Graduate School, Nanyang Technological University, Singapore \\ 639798 \\ ${ }^{\ddagger}$ Dipartimento di Chimica e Chimica Industriale, Università degli Studi di Genova, 16126 Genova, Italy \\ ${ }^{\S}$ Dipartimento di Fisica, Università degli Studi di Pavia, 27100 Pavia, Italy \\ "Dipartimento di Chimica e Biologia, Università di Salerno, 84084 Salerno, Italy \\ ${ }^{\perp}$ Istituto per la Microelettronica e Microsistemi, Consiglio Nazionale delle Ricerche, 95121 Napoli, Italy \\ ${ }^{\#}$ Centre for Disruptive Photonic Technologies, TPI, SPMS, Nanyang Technological University, Singapore 637371
}

Supporting Information

ABSTRACT: The lack of sensors for low cost, extensive, and continuous detection of vapor pollutants is a serious concern for health and safety in industrialized urban areas. Colorimetric sensors, such as distributed Bragg reflectors made of polymers, could achieve this task thanks to their low cost and easy signal transduction but are typically affected by low vapor permeability and lack of selectivity without chemical labeling. Here we demonstrate all-polymer Bragg multilayers for label-free selective detection of organic volatile compounds. The system exploits the ability of amorphous poly( $p$-phenylene oxide), PPO, to uptake large amount of guest molecules and to form cocrystalline phases with distinct optical properties. Bragg stacks embedding PPO active layers show selective colorimetric response to vapors of carbon tetrachloride and aromatic homologues, which can be revealed by the

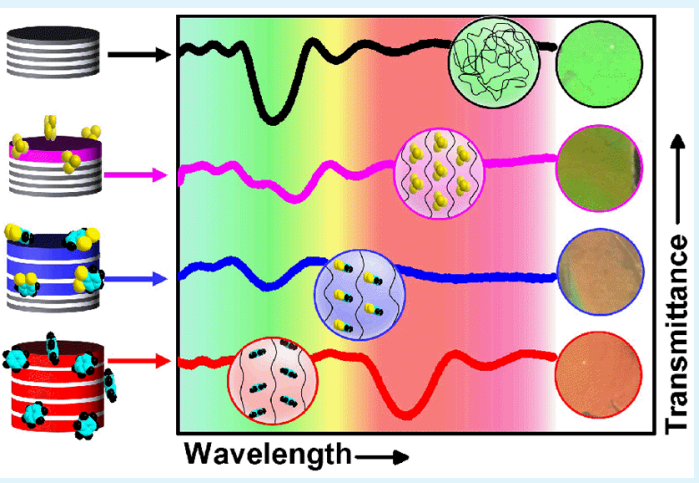
naked eye.

KEYWORDS: photonic crystal sensors, label-free selectivity, poly(p-phenylene oxide), vapor detection, colorimetric sensor

\section{INTRODUCTION}

Detection of atmospheric volatile organic compounds (VOCs) is of great importance for the evaluation of potential health risks in industrial and urban areas. ${ }^{1}$ The figure of merit of a sensor for VOCs may vary strongly depending on the polluting source. For instance, sensitivity and lower detection limit are critical to monitor operator exposures in industrial areas. Conversely, the identification of the pollutant is of primary importance in urban and rural environments due to the large number of potential sources. Quantitative monitoring is usually performed by portable detectors such as colorimetric indicator tubes, metal oxide and infrared point sensors. ${ }^{2}$ These devices can detect concentrations down to part per billion but lack of selectivity, and the presence of different analytes may easily induce false readings. VOCs identification requires instead long time sampling, 3,4 analytes separation via chromatography ${ }^{5}$ and detection via mass spectroscopy, photoionization or flame ionization detectors. ${ }^{5}$

The lack of selectivity of portable quantitative devices, together with the time and instrumentation required for qualitative analyses, are making new sensors based on the variation of photoluminescence $e^{6,7}$ and color ${ }^{8,9}$ highly interesting for environmental monitoring. Other interesting systems are based on the colorimetric or near-infrared response of chiral liquid crystals. ${ }^{10-13}$ Colorimetric devices usually rely on arrays of reactive pixels functionalized with well-defined chemical groups (i.e., labels), which interact selectively with determined analytes. These detectors can be based on metalloporphirines, ${ }^{9}$ solvatochromic agents, ${ }^{14}$ polydiacetylenes, ${ }^{15}$ or arrays of targets with different functionalization. ${ }^{16}$ These systems offer simpler analytic procedures than established qualitative techniques. On the other hand, selectivity among a broad spectrum of analytes requires the evaluation of array of labels via chemiometric analysis, which makes the signal transduction possible by suitable software.

Conversely, label-free colorimetric sensing devices offer selectivity without chemical functionalization. These systems exploit the intrinsic response to the analytes of an active

Received: August 27, 2016

Accepted: November 3, 2016

Published: November 3, 2016 
Table 1. Characteristics of Photonic Crystal-Based VOC Sensors ${ }^{a}$

\begin{tabular}{|c|c|c|c|c|c|c|c|c|}
\hline & materials & fabrication method & $\begin{array}{l}\text { transduction } \\
\text { method }\end{array}$ & $\begin{array}{l}\text { detection } \\
\text { limit }\end{array}$ & selectivity mechanism & $\begin{array}{l}\text { number of } \\
\text { analytes }\end{array}$ & reversibility & ref \\
\hline \multicolumn{9}{|c|}{ 3D structures } \\
\hline $\mathrm{P}$ & PMMA-cellulose & $\begin{array}{l}\text { self-assembly and } \\
\text { infiltration }\end{array}$ & $\Delta \lambda$ & $10^{1} \mathrm{ppm}$ & $\Delta(n \bullet d)$ & 4 & not investigated & 28 \\
\hline & PMMA & E-beam lithography & MVA & $10^{1} \mathrm{ppm}$ & silane labels (2) & 5 & yes & 67 \\
\hline \multirow[t]{2}{*}{ I } & $\mathrm{SiO}_{2}$ & self-assembly & $\Delta \lambda$ & $P_{0}$ & $\Delta n$ & 2 & yes & 24 \\
\hline & $\mathrm{SiO}_{2}$ & self-assembly & MVA & $10^{2} \mathrm{ppm}$ & silanes labels (16) & 8 & yes & 25 \\
\hline & $\mathrm{SiO}_{2}$ & self-assembly & $\begin{array}{l}\text { fluorimetry } \\
\text { (CIA + MVA) }\end{array}$ & $10^{-3} P_{0}$ & emitting labels (7) & 8 & yes & 26 \\
\hline & $\mathrm{SiO}_{2}$ & $\begin{array}{l}\text { self-assembly and } \\
\text { infiltration }\end{array}$ & $\Delta \lambda$ & $10^{3} \mathrm{ppm}$ & $\Delta n$ & 2 & yes & 27 \\
\hline & $\mathrm{TiO}_{2}-\mathrm{MOF}$ & $\begin{array}{l}\text { spin-coating and } \\
\text { annealing }\end{array}$ & CIA & $10^{-1} P_{0}$ & different MOFs (3) & 2 & yes & 29 \\
\hline & MOF & $\begin{array}{l}\text { self-assembly and } \\
\text { infiltration }\end{array}$ & $\Delta \lambda$ & $10^{1} \mathrm{ppm}$ & $\Delta n$ & 6 & yes & 23 \\
\hline & $\mathrm{SiO}_{2}$ & $\begin{array}{l}\text { self-assembly, } \\
\text { infiltration and } \\
\text { calcination }\end{array}$ & fluorimetry & $10^{-3} \mathrm{mg} / \mathrm{m}^{3}$ & not investigated & 1 & yes & 31 \\
\hline & MOF & self-assembly & $\Delta \lambda$ & $\begin{array}{l}\text { not } \\
\text { investigated }\end{array}$ & $\Delta n$ & 7 & yes & 38 \\
\hline $\mathrm{H}$ & $\mathrm{SiO}_{2}-\mathrm{PEGMA-EG}$ & $\begin{array}{l}\text { self-assembly, } \\
\text { infiltration and } \\
\text { calcination }\end{array}$ & dynamic R/T & $\begin{array}{l}\text { not } \\
\text { investigated }\end{array}$ & molecular interaction & 32 & not investigated & 30 \\
\hline & & & & D structures & & & & \\
\hline \multirow[t]{4}{*}{$\mathrm{P}$} & PS-PMMA & $\begin{array}{l}\text { spin-coating and UV } \\
\text { curing }\end{array}$ & $\Delta \lambda$ & $\begin{array}{l}\text { not } \\
\text { investigated }\end{array}$ & not investigated & 1 & not investigated & 55 \\
\hline & $\begin{array}{l}\text { PTFE-like Au } \\
\text { nanoparticles at } \\
\text { PTFE like }\end{array}$ & ion sputtering & $\Delta \lambda$ & $0.05 P_{0}$ & $\Delta(n \bullet d)$ & 3 & yes & 54,56 \\
\hline & PS-CA & spin-coating & dynamic $\mathrm{R} / \mathrm{T}$ & $10^{-1} \mathrm{ppm}$ & not investigated & 1 & not investigated & 21,57 \\
\hline & PPO-CA & spin-coating & dynamic R/T & $10^{1} \mathrm{ppm}$ & $\begin{array}{l}\text { molecular interaction/ } \\
\text { phase transition }\end{array}$ & 4 & no & $\begin{array}{l}\text { this } \\
\text { work }\end{array}$ \\
\hline \multirow[t]{12}{*}{ I } & porous silicon & electrochemical etching & $\Delta \lambda$ & $10^{2} \mathrm{ppm}$ & silane labels (7) & 2 & yes & 33 \\
\hline & porous silicon & electrochemical etching & $\Delta \lambda$ & $<1$ Torr & $\begin{array}{l}\Delta n \text { at different } \\
\text { temperature }\end{array}$ & 3 & yes & 34 \\
\hline & porous silicon & electrochemical etching & dynamic R/T & $10^{2} \mathrm{ppm}$ & $\begin{array}{l}\Delta n \text { in stacked DBRs with } \\
\text { decreasing porosity }\end{array}$ & 7 & yes & 36 \\
\hline & $\mathrm{SiO}_{2}-$ activated carbon & electrochemical etching & $\Delta \lambda$ & $10^{1} \mathrm{ppm}$ & $\Delta n$ & 4 & yes & 68 \\
\hline & $\mathrm{SiO}_{2}-\mathrm{TiO}_{2}$ & $\begin{array}{l}\text { spin-coating and } \\
\text { annealing }\end{array}$ & CIA & $\begin{array}{l}\text { not } \\
\text { investigated }\end{array}$ & silane labels (9) & 6 & yes & 42 \\
\hline & $\mathrm{SiO}_{2}-\mathrm{TiO}_{2}$ & $\begin{array}{l}\text { spin-coating and } \\
\text { annealing }\end{array}$ & $\Delta \lambda$ & $10^{-2} P_{0}$ & $\Delta n$ & 1 & not investigated & 69 \\
\hline & $\mathrm{SiO}_{2}-\mathrm{TiO}_{2}$ & $\begin{array}{l}\text { spin-coating and } \\
\text { annealing }\end{array}$ & $\Delta \lambda$ & $\begin{array}{l}\text { not } \\
\text { investigated }\end{array}$ & $\Delta n$ & 4 & yes & 32 \\
\hline & $\mathrm{SiO}_{2}-\mathrm{TiO}_{2}$ & $\begin{array}{l}\text { spin-coating and } \\
\text { annealing }\end{array}$ & $\Delta \lambda$ & $10^{1} \mathrm{ppm}$ & not investigated & 1 & yes & 39 \\
\hline & $\mathrm{SiO}_{2}-\mathrm{TiO}_{2}$-zeolite & $\begin{array}{l}\text { spin-coating and } \\
\text { annealing }\end{array}$ & $\Delta \lambda$ & $10^{-1} P_{0}$ & not investigated & 1 & not investigated & 40 \\
\hline & $\mathrm{TiO}_{2}$-zeolite & $\begin{array}{l}\text { spin-coating and } \\
\text { annealing }\end{array}$ & $\Delta \lambda$ & $10^{-1} P_{0}$ & $\begin{array}{l}\Delta n \text {-zeolite cage size } \\
\text { section }\end{array}$ & 4 & not investigated & 43 \\
\hline & $\mathrm{Nb}_{2} \mathrm{O}_{5}$-zeolite & $\begin{array}{l}\text { spin-coating and } \\
\text { annealing }\end{array}$ & $\Delta \lambda$ & $10^{2} \mathrm{ppm}$ & not investigated & 1 & yes & 37 \\
\hline & $\begin{array}{l}\mathrm{TiO}_{2}-\text { mixed metal } \\
\text { oxides }\end{array}$ & $\begin{array}{l}\text { spin-coating and } \\
\text { annealing }\end{array}$ & $\Delta \lambda$ & $\begin{array}{l}\text { not } \\
\text { investigated }\end{array}$ & $\Delta n$ & 4 & yes & 35 \\
\hline $\mathrm{H}$ & $\mathrm{V}_{2} \mathrm{O}_{5}-\mathrm{PMMA}$ & spin-coating & $\Delta \lambda$ & $\begin{array}{l}\text { not } \\
\text { Investigated }\end{array}$ & $\begin{array}{l}\mathrm{V}_{2} \mathrm{O}_{5} \Delta n-\mathrm{PMMA} \\
\Delta(n \bullet d)\end{array}$ & 2 & not investigated & 41 \\
\hline
\end{tabular}

${ }^{a} \mathrm{P}=$ polymer, $\mathrm{I}=$ inorganic, $\mathrm{H}=$ hybrid polymer-inorganic, $\mathrm{MVA}=$ multivariate analysis, CIA = color imagery analysis, $\mathrm{MOF}=$ metal - organic framework, $\mathrm{R} / \mathrm{T}=$ reflectance or transmittance spectroscopy, $\Delta n=$ refractive index variation, $\Delta(n \bullet d)=$ optical thickness variation, $\Delta \lambda=\mathrm{PBG}$ wavelength variation.

material. In this regards, photonic crystal based optical sensors are largely investigated thanks to low fabrication costs and ease of integration in lab-on-a-chip devices. ${ }^{17-20}$ Photonic crystal sensing relies on the optical response generated by the variation of effective refractive index $\left(n_{\text {eff }}\right)$ and periodicity of a dielectric lattice. $^{21,22}$ These variations can be induced by the intercalation of an analyte within the structure and in principle, allow selective colorimetric responses. ${ }^{21}$ Indeed, highly permeable porous lattices such as synthetic opals, ${ }^{23-31}$ porous inorganic $^{32-40}$ and hybrid ${ }^{41}$ distributed Bragg reflectors (DBRs) have been widely investigated as colorimetric detectors for gas and vapor organic pollutants. Among these structures, inorganic mesoporous DBRs are interesting thanks to their selectivity (Table 1). ${ }^{32,35,37,42,43}$ However, in these systems the spectral 
variation induced by the analytes is often moderate and its interpretation requires complicated chemiometric analyses. ${ }^{44}$ This is due both to the high dielectric contrast among the components, that generates broad photonic band-gaps (PBGs), and to the rigidity of the structure, which only allows refractive index variations, preventing swelling phenomena.

The issues related to inorganic DBRs, can be overcame by polymer structures. First of all, polymer multilayers can be grown by several simple and fast techniques such as copolymers self-assembly, ${ }^{45}$ deep-coating, ${ }^{46}$ spin-coating, ${ }^{47-51}$ or even by coextrusion at the industrial scale. ${ }^{52}$ Moreover, the relatively low polymer dielectric contrast allows narrow PBGs, which are necessary for the detection of very small spectral variations. This effect is further enhanced by the high analyte uptake typical of selected polymer media, which allows their strong swelling. Swelling induces both periodicity and refractive index variations, which amplify the spectral response to small environmental concentration of analytes. Thanks to these properties, polymer DBR sensors possess high sensitivity, and their color variation upon exposure to analytes is easily detectable, even by the naked eye. ${ }^{21,53}$ Polymer DBRs have been successfully employed for selective detection of chemical compounds in the liquid phase ${ }^{53}$ but only few studies dealt with the detection of vapors, ${ }^{21,54-56}$ and selectivity remains an unsolved issue. In a previous work, we reported on spun-cast DBRs made of cellulose acetate and $\mathrm{ZnO}$-polystyrene nanocomposite, demonstrating the fastest response to concentration of toluene down to $0.5 \mathrm{ppm} .^{21,57}$ Despite the sensitivity of these systems, VOCs discrimination still represented a drawback.

In this work, we demonstrate highly selective polymer DBR sensors without chemical labels, that make use of the supramolecular response of poly ( $p$-phenylene oxide) (PPO) to specific organic compounds. The diffusion of certain molecules within amorphous PPO induces the formation of cocrystalline phases where guest molecules are included within the polymer lattice. Guest desorption results in the formation of a typical nanoporous crystalline phase specific for any analyte. ${ }^{58-60}$ The different optical properties of cocrystalline and nanoporous crystalline phases deeply modifies the DBR reflectance spectrum throughout the visible spectral range, inducing chromatic changes that can be detected by the naked eye. This mechanism, together with the different response kinetics typical of any analyte, allows the effective label-free selective response. As a proof of principle, we study the characteristic optical response of a PPO-cellulose acetate (CA) DBR to vapors of carbon tetrachloride (CTC), benzene $(\mathrm{BEN})$, and 1,2-dichlorobenzene (o-DCB).

\section{EXPERIMENTAL SECTION}

2.1. Thin Film Fabrication and Characterization. Before implementing PPO as active medium into the DBR sensors, its vapor induced phase transition was assessed by infrared reflection absorption spectroscopy (IRRAS) and spectroscopic ellipsometry. For this purpose, a PPO (Sabic, $M_{\mathrm{w}}=50000$ )toluene (Sigma-Aldrich) solution with concentration of $3 \mathrm{wt} \%$ was spun-cast on gold coated glass substrates using a rotation speed of $5000 \mathrm{rpm}$ for $\sim 60 \mathrm{~s}$. Both IRRAS and spectroscopic ellipsometry measurements were performed on PPO thin films as cast. The films were then exposed to vapors of 1,2dichlorobenzene, benzene and carbon tetrachloride at room temperature for $30 \mathrm{~min}$ in saturation condition, and further analyzed. It is worth to stress that, we collected the ellipsometric data before and after an exposure time of 30 min for single PPO thin films because time-resolved ellipsometry within a closed environment enriched by vapors could easily led to data misinterpretation due to the complicate geometry of the system, and to the long experiment duration. As a consequence, the data are representative of the PPO film after guest desorption.

We also retrieved the optical functions of cellulose acetate (Sigma-Aldrich, $M_{\mathrm{w}}=60000$ ) thin films fabricated by spincoating at $5000 \mathrm{rpm}$ for $30 \mathrm{~s}$ of 4-hydroxy-4-methylpentan-2one solution (Sigma-Aldrich) with concentration $2.5 \% \mathrm{wt}$.

The IRRAS spectra (600 scans and $2 \mathrm{~cm}^{-1}$ resolution) were collected using a Bruker Tensor 27 FTIR spectrometer coupled to a PMA50 external module equipped with a linear KRS5 linear polarizer, a $\mathrm{ZnSe} 50 \mathrm{kHz}$ photoelastic modulator (PEM by HINDS), an optical filter transmitting below $4000 \mathrm{~cm}^{-1}$, a variable angle reflection accessory, and a narrow band mercury-cadmium-telluride ( $\mathrm{HgCdTe})$ detector. An incidence angle of $85^{\circ}$ was used.

Spectroscopic ellipsometry data were recorded using a phase modulated spectroscopic ellipsometer (UVSEL by Jobin Yvon Horiba) with a wavelength scanning range from 400 to 1000 $\mathrm{nm}$ at variable angle of incidence between $55^{\circ}$ and $65^{\circ}$. The acquired data were fit to an optical model of the sample, in which the dispersion of the CA and PPO films were assumed to follow the Cauchy's dispersion relation, leading to film thickness and refractive index $n(\lambda)$. The film structure used in the model consists of a homogeneous bulk polymeric film and an outmost layer, described by a Bruggeman effective medium approximation ${ }^{61}$ mixture of bulk material and voids, with a lower density.

2.2. DBR Sensors. DBR were fabricated by alternated spincoating of PPO-toluene and CA-4-hydroxy-4-methylpentan2 -one solutions with concentration of $3 \mathrm{wt} \%$ and rotation speed of $5000 \mathrm{rpm}$ for $60 \mathrm{~s}$ on glass substrates.

For all the DBR samples, reflectance data were collected with homemade setups based on optical fiber using a Y-fiber probe and an Avantes AvaSpec-2048 spectrometer (200-1150 nm, resolution $1.4 \mathrm{~nm}$ ). The light source was a combined deuterium-halogen Micropak DH2000BAL.

The sensor optical response to vapor exposure was measured at $20{ }^{\circ} \mathrm{C}$ and $1 \mathrm{~atm}$ in a closed container where a $0.5 \mathrm{~mL}$ of liquid VOC was previously placed to saturate the environment. The partial pressure for the four vapors in the given condition was calculated ${ }^{62}$ as carbon tetrachloride, $11.95 \mathrm{kPa}$; benzene, $10.5 \mathrm{kPa}$; 1,2-dichlorobenzene, $0.13 \mathrm{kPa}$; and toluene, $2.8 \mathrm{kPa}$. The optical response was recorded collecting transflectance measurements using the immersion fiber probe illustrated in Figure S1 and the fiber setup previously described.

2.3. Spectra Modeling. The spectra simulations were performed using a Matlab homemade code based on the transfer matrix method as reported in a previous work. ${ }^{21}$ For the unexposed sample, we used the measured refractive index dispersion and layer thicknesses for $\lambda / 4$ condition as inputs. ${ }^{47}$

\section{RESULTS AND DISCUSSION}

3.1. Vapor-Induced Phase Transition in PPO Thin Films. Figure 1 reports the IRRAS spectra of the polymer films before (black line) and after crystallization by exposure to VOC vapors for $30 \mathrm{~min}$ at room temperature. We focus our attention on the region between 800 and $900 \mathrm{~cm}^{-1}$, where the shift toward lower energy, and sharpening of the peaks assigned to the in-phase $\left(860 \mathrm{~cm}^{-1}\right)$ and the out-of-phase $\left(831 \mathrm{~cm}^{-1}\right)$ out- 


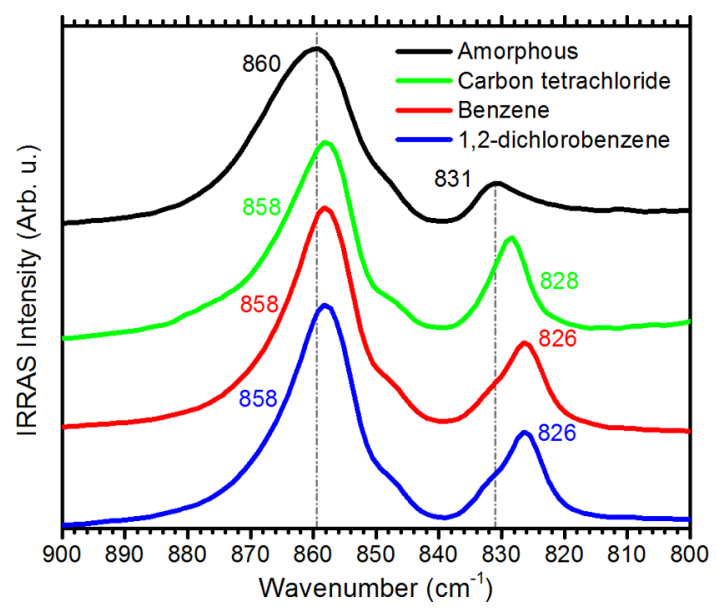

Figure 1. IRRAS spectra of PPO thin film before (black line) and after crystallization induced by suitable guests: CTC (green), BEN (red), and $o$-DCB (blue).

of-plane $-\mathrm{CH}$ wagging are known fingerprints of amorphous and crystalline PPO in bulk samples. ${ }^{60,63,64}$

The exposure to the four vapors induces a shift to lower frequencies and sharpening of both the peaks, clearly showing that the crystallization occurs in all the samples. Moreover, the initial mode positioned at $831 \mathrm{~cm}^{-1}$ becomes a shoulder in the new structure, indicating the coexistence of an amorphous and a crystalline phase in the exposed PPO thin films. ${ }^{64}$ The absence of vibration peaks of the VOCs (after desorption in air) indicates the formation of PPO films exhibiting different nanoporous crystalline modifications, which depend on the guest. ${ }^{65}$ Identical behavior is also observed upon exposure to toluene (TOL) vapors (Figure S2).

The thin film refractive indexes $(n)$ retrieved from ellipsometry before and after PPO crystallization can provide additional information about the new nanoporous crystalline phases. The data in Figure 2a show that amorphous PPO refractive index ranges from 1.62 at $400 \mathrm{~nm}$ to 1.56 at $1000 \mathrm{~nm}$, while its extinction coefficient is negligible in this spectral range. In the same figure, we also report the dispersion of the optical function determined for cellulose acetate thin films, which

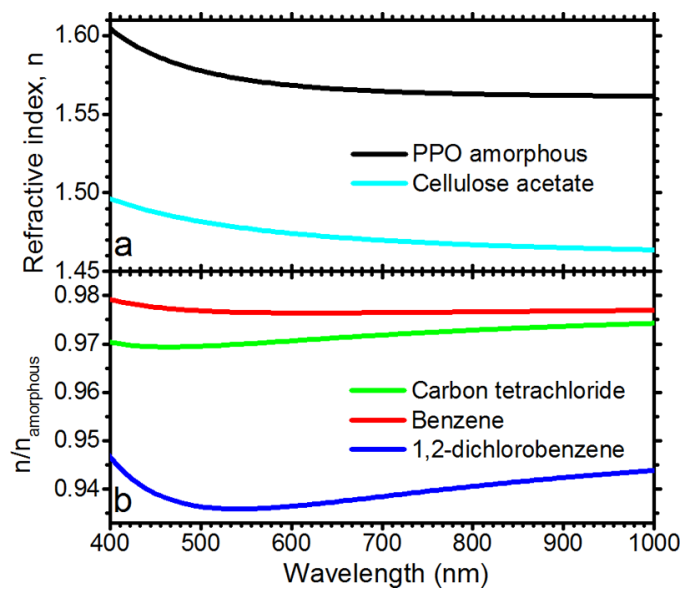

Figure 2. (a) Refractive index dispersion of amorphous PPO (black) and CA (cyan). (b) Fractional refractive index variation (n/ $\mathrm{n}$ amorphous) of the PPO thin films after crystallization induced by exposure to different organic guests: CTC (green), BEN (red), and oDCB (blue) vapors. agrees well with previous reports. ${ }^{48}$ The PPO refractive index decreases upon crystallization and guest desorption of $2.3 \%$ for benzene, $3.0 \%$ for carbon tetrachloride, and $6.4 \%$ for 1,2 dichlorobenzene at $560 \mathrm{~nm}$. The reduction of refractive index can be related to the lower density of the nanoporous crystalline phases $\left(\sim 1.009 \mathrm{~g} / \mathrm{cm}^{3}\right)$ with respect to the amorphous phase $\left(1.016 \mathrm{~g} / \mathrm{cm}^{3}\right) .{ }^{66}$ The differences between the new $n$ values of semicrystalline PPO films is likely to be driven by the bulkiness of the guests. Indeed, the VOC van der Waals volumes $\left(v_{\mathrm{BEN}}=82 \AA^{3}, v_{\mathrm{CTC}}=84 \AA^{3}\right.$, and $v_{o \text { - } \mathrm{DCB}}=110$ $\AA^{3}$ ) scale approximately as the reduction of refractive index. This behavior suggests that the formation of different PPOVOC cocrystalline phases, and of the corresponding nanoporous crystalline phases upon guest desorption, depend on the guest molecular size. ${ }^{60,63}$

3.2. PPO-CA Distributed Bragg Reflectors. Amorphous PPO thin films were then implemented as the active sensing region in all-polymer DBRs. Figure 3a shows the architecture of
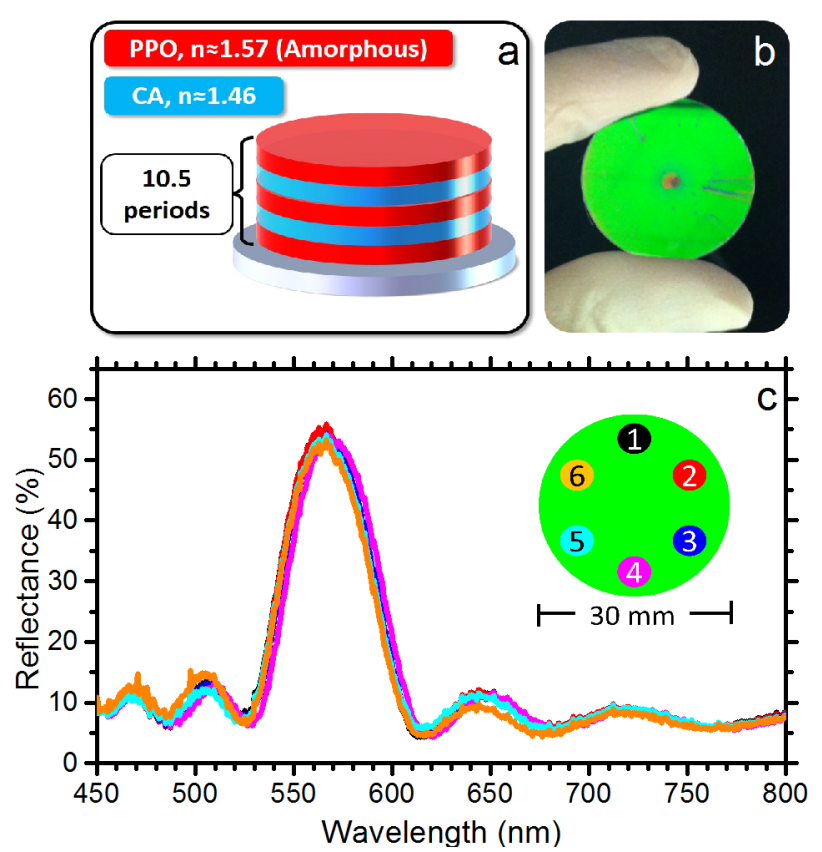

Figure 3. (a) Schematic and (b) photograph of a typical DBR sample. (c) Reflectance spectra collected from six different spots of a CAPPO DBR on glass substrate.

the DBR sensing platform grown by spin-coating deposition of 21 alternated thin films of PPO and CA, as described in the Experimental Section. Figure $3 \mathrm{~b}$ shows the photograph of a 30 $\mathrm{mm}$ diameter sample showing a vivid green color generated by the DBR PBG. The PBG is in turn detectable in the spectra of Figure $3 c$ as an intense peak in the reflectance spectrum centered in the green region of the visible spectrum at $\lambda \approx 560$ $\mathrm{nm}$. The nearly perfect superposition of the spectra collected over different spots on the sample surface (see inset of Figure $3 \mathrm{c}$ ) proves the large homogeneity of the DBR. Furthermore, the background of all the spectra shows a Fabry-Pérot interference pattern that further reveals the excellent optical quality of the structure. The relatively low dielectric contrast between PPO and CA, makes the photonic band gap sharp enough to allow an easy detection of minor spectral changes.

3.3. Label-Free Selectivity. The DBR capability to selectively detect VOCs was assessed by exposing three 

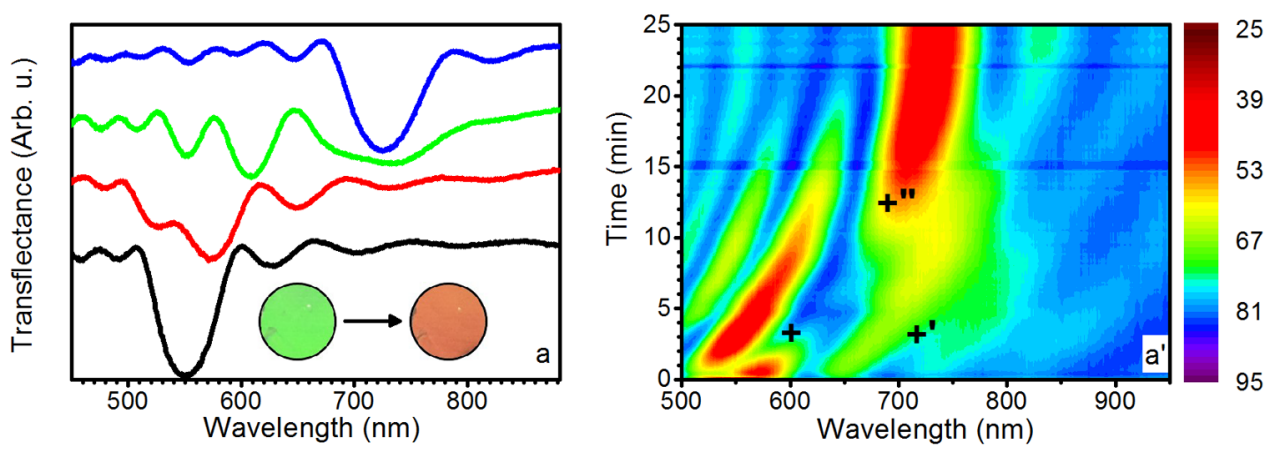

1,2-DICHLOROBENZENE
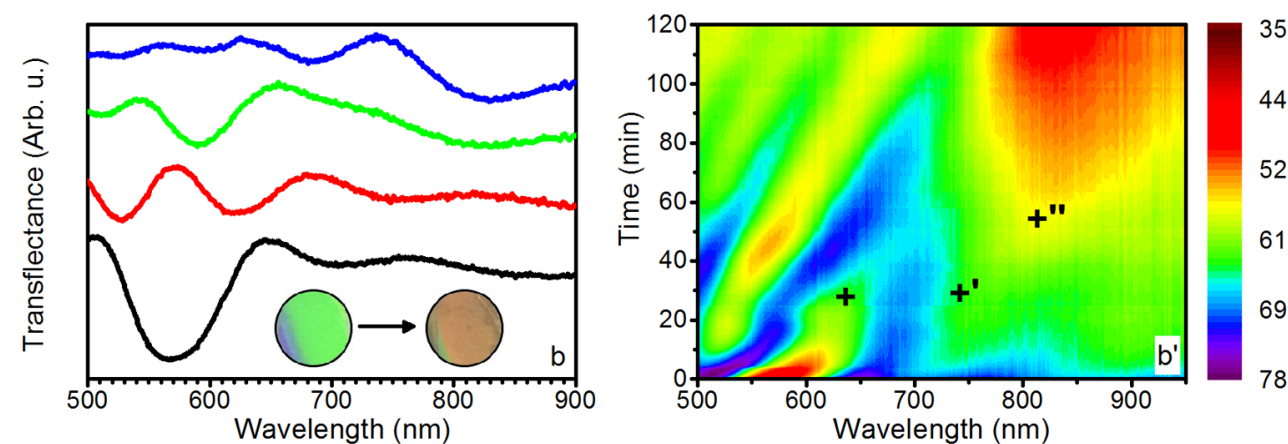

CARBON TETRACHLORIDE
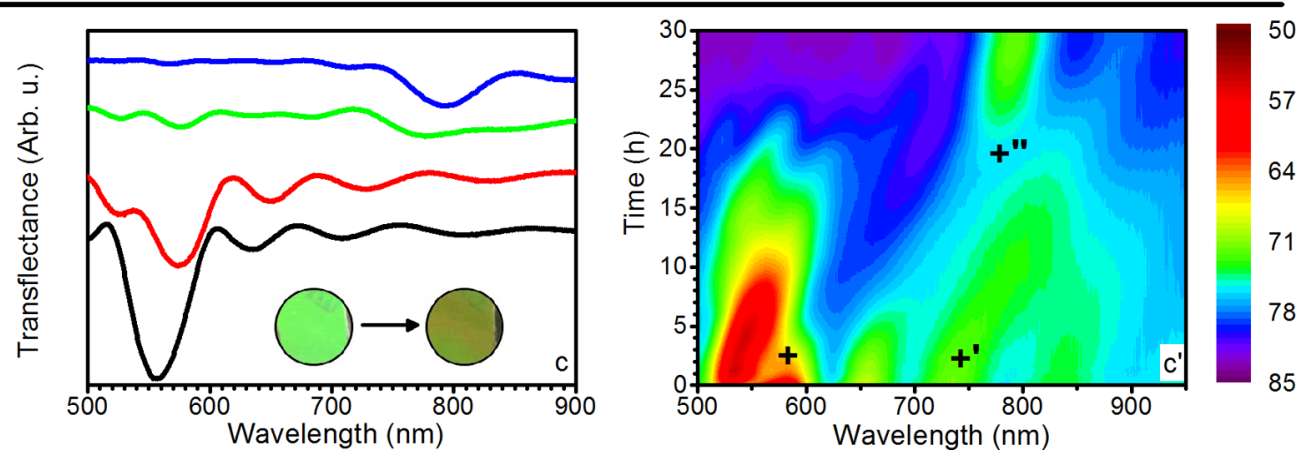

Figure 4. Time resolved optical response of PPO-CA sensors to (a) BEN, (b) o-DCB, and (c) CTC. The circular insets show the photographs of the samples before and after $40 \mathrm{~min}$ of exposure. $\left(\mathrm{a}^{\prime}, \mathrm{b}^{\prime}\right.$, and $\left.\mathrm{c}^{\prime}\right)$ Time evolution of the spectrum reported as contour-plots spectra.

portions of the same sample to saturated environments of carbon tetrachloride, benzene and 1,2-dichlorobenzene vapors. The evolution of the transflectance DBR spectrum was monitored over time during the guest absorption. Figure $4 a-$ c show the evolution of the spectra at selected exposure times. Figure $4 a^{\prime}-c^{\prime}$ show the spectra contour-plots: the PBG (with lower transflectance value) is visible in red color tones, while the background (with higher transflectance value) is in blue tones (see Figure S3 for the corresponding spectra).

Figure 4 shows that the vapor exposures induce a red-shift of the DBR PBGs with different magnitude and kinetics for the three VOCs. In the case of benzene, the exposure induces a progressive swelling of the PPO layers and a red-shift of the PBG $\Delta \lambda_{\mathrm{BEN}}=189 \mathrm{~nm}$ occurring within $1 \mathrm{~h}$ of exposure. In details, the top panels of Figure 4 show that the PBG red-shifts of $\sim 20 \mathrm{~nm}$ during the first $15 \mathrm{~s}$ of exposure (marked by + in Figure $\left.4 a^{\prime}\right)$. At longer exposure time, the vapor penetrates deeper into the DBR inducing the swelling of the layers exposed to the environment rich in benzene, while the bottom structure (close to the glass substrate) remains unaffected. The contemporary presence of swollen and unaffected layers in the
DBR allows the detection of two coexisting PBGs in its reflectance spectrum. The first PBG is visible at $\sim 560 \mathrm{~nm}$ (unswollen bottom structure) and the second at $\sim 710 \mathrm{~nm}$ (swollen top DBR) as shown by the green line of Figure $4 \mathrm{a}$ and marked with + and $t^{\prime}$ in Figure $4 a^{\prime}$. Before reaching the equilibrium condition, the top layers have different thickness. As a consequence, the PBG positioned at longer wavelength appears spectrally broad. With further benzene uptake, the intensity and symmetry of this peak keeps increasing. Contemporary, the benzene molecules diffuse to the bottom DBR layers and the intensity of the PBG positioned at shorter wavelength starts fading. Indeed, after $\sim 12$ min of exposure only the long-wavelength peak is visible (blue line in Figure 4a and marked with $+^{\prime \prime}$ in Figure $\left.4 a^{\prime}\right)$. At longer times, the DBR keeps absorbing benzene and the new PBG further red-shifts by additional $30 \mathrm{~nm}$ until all the layers are fully swollen. This behavior was previously observed and modeled for the progressive swelling of DBRs made by polystyrene nanocomposites and cellulose acetate exposed to toluene vapors. ${ }^{21}$

In the case of 1,2-dichlorobenzene, the spectral response has the same discontinuous behavior observed for benzene. 
Conversely, the stationary condition is reached for a PBG shift $\Delta \lambda_{\text {o-DCB }}=257 \mathrm{~nm}$ within $2 \mathrm{~h}$ of exposure, showing that the kinetics is much slower. In this case, the vapor penetrating into the structure progressively destroys the $\mathrm{DBR}$, thus reducing the intensity of its PBG within 25 min (marked with + in Figure $\left.4 b^{\prime}\right)$. At longer time, the periodicity condition is restored and a broad structure, assigned to the swollen layers, arises at about $820 \mathrm{~nm}$ (green line of Figure $4 \mathrm{~b}$ and $+^{\prime}$ mark in Figure $4 \mathrm{~b}^{\prime}$ ). The further penetration of 1,2-dichlorobenzene, shifts the PBG of other $100 \mathrm{~nm}$ within $120 \mathrm{~min}$ of exposure (blue line of Figure $4 \mathrm{~b}$ and $t^{\prime \prime}$ mark in Figure $\left.4 \mathrm{~b}^{\prime}\right)$. Comparison of the DBR response to the two aromatic vapors shows that 1,2dichlorobenzene induces a red-shift 1.6 times larger than benzene. This effect is assigned to the high molecular hindrance of the substituted aromatic ring, which is likely to prompt a larger swelling of the DBR layers than benzene. Such a strong thickness variation also decreases the interfacial tension between PPO and CA layers, inducing interfacial disorder, and thus an inhomogeneous broadening of the PBG.

When the sensor is exposed to carbon tetrachloride, the equilibrium condition occurs on a much longer time scale than for the aromatic homologues. After $2 \mathrm{~h}$ in the carbon tetrachloride environment, the intensity of the band gap assigned to the unswollen DBR fades (green line of Figure $4 \mathrm{c}$ and + mark in Figure $4 c^{\prime \prime}$ ), while the PBG arising from the top swollen layers increases in intensity and symmetry (blue line of Figure $4 \mathrm{c},+^{\prime}$ and $+^{\prime \prime}$ marks in Figure $4 \mathrm{c}^{\prime}$ ) and keeps evolving for $\sim 30$ h. Globally the PBG shows a shift $\Delta \lambda_{\text {CTC }}=235 \mathrm{~nm}$.

For the sake of curiosity, we also investigated the optical response of the sensor during exposure to toluene, as reported in Figures S3 and S4. Compared to the other aromatics, the spectral evolution is simpler and is characterized by the presence of a single PBG monotonically moving to the red part of the visible spectrum. Here the PBG peak, initially centered at $560 \mathrm{~nm}$ shifts monotonically until $740 \mathrm{~nm}$ in about $1 \mathrm{~h}$.

The selective optical response of the sensor is clearly represented by the insets of Figure $4 a-c$, showing the actual photographs of three samples before and after $\sim 40 \mathrm{~min}$ of exposure. The sensor exposed to benzene appears initially green while, after the exposure the color changes to a vivid and bright red due to the PBG now positioned in the red region. Differently, Figure $4 \mathrm{~b}$ shows that when exposed to 1,2dichlorobenzene, the sensor appears reddish with a much darker tone compared to the previous case. This difference is attributed to the formation of a swollen structure with a spectrally broad PBG positioned in the near-infrared part of the spectrum. Figure $4 \mathrm{c}$ shows that the color of the sample exposed to carbon tetrachloride changes slightly. The sample surface appears green with some reddish shadow. At $40 \mathrm{~min}$ of exposure, the slow response of the sensor to carbon tetrachloride vapors allows the coexistence of two PBGs: one in the green region assigned to the unswollen top layers of the DBR and a broad one centered in the near-infrared interval. These differences are also highlighted in Figure S4, which reports the evolution of the spectrum of all the samples within the same spectral and time domain.

3.4. Long-Term Response. All the spectral variations observed in Figure 4 and Figure S4 are due to the formation of different PPO cocrystalline phases with the different guests. ${ }^{60,63}$ This is also reflected by the long-term optical response of the sensors showing that after guest desorption the DBR retains a nanoporous crystalline phase. Figure 5 compares the calculated and experimental reflectance spectra of a DBR collected before

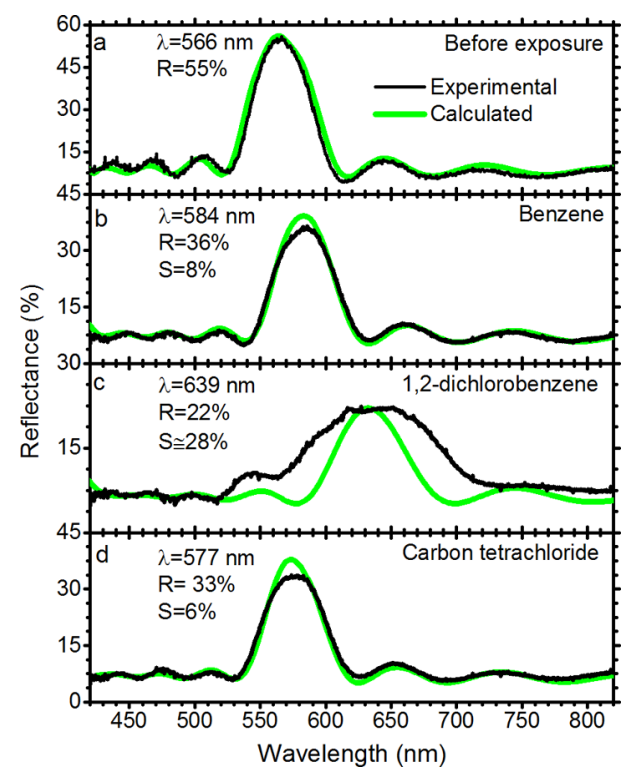

Figure 5. Experimental and calculated reflectance spectra of PPO-CA sensors a) before exposure, and after exposure and desorption for $24 \mathrm{~h}$ of b) BEN, c) o-DCB and d) CTC vapors.

exposure (a) with those collected after guest exposure and desorption for $24 \mathrm{~h}$ in room condition of benzene (b), 1,2dichlorobenzene (c) and carbon tetrachloride (c). As mentioned above, the DBR initially shows a PBG at $\lambda=556$ $\mathrm{nm}$ with reflectance intensity $\mathrm{R}=55 \%$ and typical interference pattern (black line in Figure 5a). The data are in full agreement with the spectrum calculated for a DBR with thicknesses of 91 and $96 \mathrm{~nm}$ for the PPO and CA layers, respectively (green line in Figure 5a).

Independently of the VOC guest, the PBG does not return to the initial condition after exposure and desorption of the guest. When benzene is desorbed, the band gap intensity is indeed reduced to $\mathrm{R}=36 \%$ while its spectral position remains redshifted to $584 \mathrm{~nm}(\Delta \lambda=28 \mathrm{~nm}$, black line in Figure $5 \mathrm{~b})$. The interference pattern in the spectrum is well-defined, indicating that the initial optical quality of the system is unchanged. The reflectivity data collected after desorption are in full agreement with the spectrum calculated using the refractive indexes reported in Figure 2 and considering a swelling degree $(S)$ of the PPO layer thickness of $8 \%$ with respect to the pristine films (Figure $5 b$, green line).

Conversely, after 1,2-dichlorobenzene desorption, the interference pattern is irregular and has low intensity. The PBG is strongly shifted to $639 \mathrm{~nm}(\Delta \lambda \cong 83 \mathrm{~nm})$, and its intensity approaches $\mathrm{R}=22 \%$. Moreover, the peak is characterized by the inhomogeneous spectral broadening induced by the strong swelling of the PPO layers detected during the exposure (blue line of Figure $4 \mathrm{~b}$ ). These features indicate that the bulky molecule strongly affects the photonic structure even on long time scales. With the green line of the same Figure, we report the simulated spectrum for the structure. The strong disagreement with the PBG measured experimentally confirms the disruptive effect of 1,2-dichlorobenzene on the dielectric lattice. On the other hand, the peak intensity and its spectral position can be well captured by the simulation $(S=28 \%)$, thus confirming the reduction of the dielectric contrast within the DBR. 
Desorption of carbon tetrachloride induces a PBG with intensity of $R=33 \%$ positioned at $577 \mathrm{~nm}(\Delta \lambda=11 \mathrm{~nm})$. The spectrum is in agreement with a swelling of the PPO layers equal to $6 \%$.

Comparing the data collected after VOCs desorption with the IRRAS spectra of Figure 1 and with the refractive index variation of Figure 2, we can reasonably conclude that, on the long-term, the PPO layers retain a crystalline phase with nanoporous character having lower density and lower refractive index than the pristine amorphous films. The PBG positioned at longer wavelengths with respect to the initial condition also confirms the presence of porosity typical of the nanoporous crystalline structure indicating the irreversibility of the process. The low density phase has indeed higher volume and thickness than the initial amorphous layers. ${ }^{64}$ The strong red-shifts observed in Figure 4 for all the VOC guests can then be attributed to two phenomena: first, the formation of cocrystalline phases including guest molecules and second, the swelling of the amorphous phase already observed for other systems. ${ }^{21}$

3.5. Selectivity Mechanism. To better illustrate the phenomena occurring within the DBR, Figure 6 schematizes the processes inducing the behavior illustrated in Figures 4 and 5. When the DBR is exposed to an environment rich in VOC vapors (A), the analyte penetrates within the structure starting from the layer contacting the environment rich in VOC and inducing the swelling and crystallization of the amorphous PPO top layers (B in Figure 6 and Supporting Figure S5 and S6).

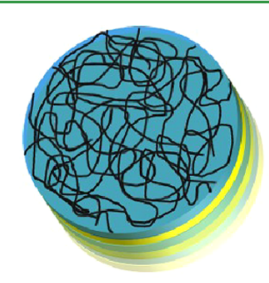

A

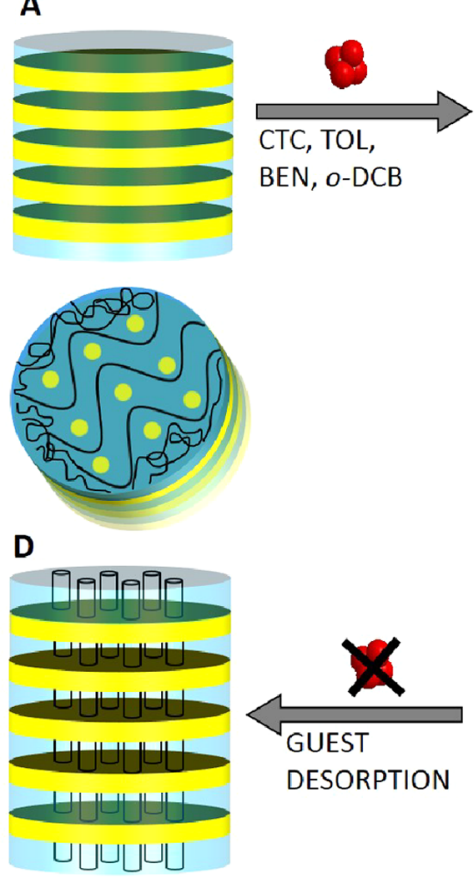

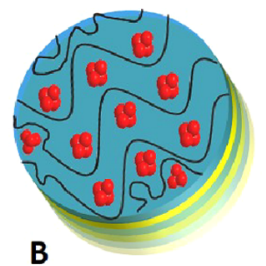

B
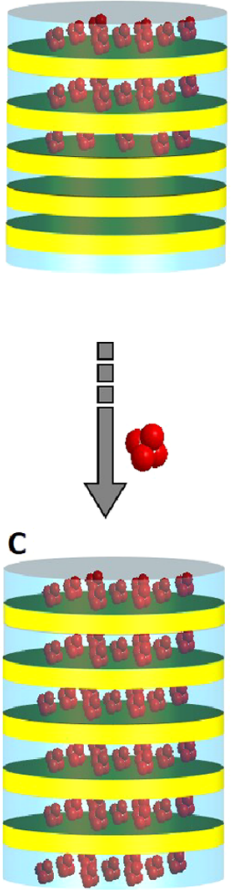

Figure 6. Schematic of the formation of PPO-VOC cocrystals within the DBR during vapor exposure (A, B) and of the guest desorption (C, D).
The different degree of swelling interrupts the DBR periodicity resulting in the coexistence of two PBGs, as observed in Figure 4. At longer exposure time, the analyte penetrates within all the DBR layers causing the disappearance of the PBG assigned to the unswollen structure and a further red-shift of the PBG assigned to the swollen one ( $\mathrm{C}$ in Figure 6 and $+{ }^{\prime \prime}$ marks in Figure $\left.4 a^{\prime}-c^{\prime}\right)$. Once the VOC vapors are removed from the DBR environment, the guest is desorbed within $1 \mathrm{~h}$ in room condition ( $D$ in Figure 6 and full kinetics in Figure S7). After guest desorption the PPO thin films retain a nanoporous crystalline phase having different density, thickness and optical properties than the initial amorphous phase. Indeed, the DBR PBGs have different spectral position and intensity than the starting samples containing the amorphous phase (Figure 5). The different response kinetics of the process for the analyzed VOC vapors, together with the different spectral shift allowed by the analyte generate the fingerprint response typical of the investigated molecule.

Notwithstanding reversibility is usually advantageous for a sensing device, the low material and fabrication costs, joined to chemical selectivity achieved without using any specific chemical label, might make these easily readable sensors viable for high technological readiness level devices. Moreover, the irreversible nature of the PPO phase transition allows label-free selectivity even to vapor of molecules with very similar structure.

To better highlight the capabilities provided by our proof-ofprinciple PPO-CA sensor, Table 1 summarizes its characteristic and compare them with those of photonic crystal sensors recently reported in literature. Beside the mechanisms allowing selectivity, the table also focuses on fabrication processes, transduction methods and low detection limit, already discussed in the introduction.

We can distinguish three main selectivity mechanisms. The first includes devices based on the use of arrays of labels, which provide selectivity trough chemiometric analyses of the optical responses, ${ }^{25,28,33,42,67}$ or on more complicated optical techniques such as fluorimetry. ${ }^{26,31,33}$ As discussed above, these labeled systems suffer of complicated signal transduction methods.

The second mechanism is based on the PBG spectral shift induced by the variation of either the effective refractive index $^{23,24,27,32,35,38,43,68,69}$ or the optical thickness of the photonic crystal. ${ }^{28,54,56}$ Because of the similarity of VOC refractive indexes in the vapor phase, these systems suffer from three drawbacks. First, to allow detectable responses, the analyte must condensate within the photonic crystal porosity. Second, being the response of the system related to its effective refractive index, which in turn is a function of the volume fraction of the photonic crystal components, the void volume must be maximized, still allowing capillary condensation. Third, disentangling analytes having different refractive index could be complicate within specific concentration ranges. Indeed, low analyte concentrations may not allow significant optical variations. ${ }^{69}$ Moreover, low concentrations of an analyte with high refractive index induces the same optical changes of large concentrations of another analyte having a lower refractive index value. ${ }^{70}$ The chemical selectivity of these system can be improved by including a size-selective materials such as a zeolite thin films in the photonic crystal, ${ }^{43}$ by analyzing the combined response of two or more DBR having different porosity or periodicity, ${ }^{29,36}$ or by introducing different variables (e.g., temperature) during the sensing process. ${ }^{34}$ These approaches 
enhance the selectivity but make the signal transduction more complicated.

The last selectivity mechanism reported is the one used in the present work, and is based on the different chemical and physical affinity between the photonic crystal components and the analytes. For instance, the response kinetics can be modified by introducing free volume within a polymer DBR using nanocomposite matrices. ${ }^{21}$ These differences allow a diverse permeation kinetics which, together with the spectral shift induced by the analyte provide selectivity. In this case the permeation kinetics and the PBG spectral shift are induced by a variety of parameters including the analyte molecular size, the chemical affinity between the analyte and the polymer media, the media free volume, eventual phase transitions, and many others. Beside the present work, this mechanism has been reported only few times. The first example is represented by a $\mathrm{SiO}_{2}$ opals infiltrated with a poly(ethylene glycol) methacrylate (PEGMA) gel swollen with ethylene glycol (EG). ${ }^{30}$ Here, the analyte can diffuse into the gel or extract the glycol with different kinetics depending on its polarity, viscosity and chemical affinity. In another case, three porous silicon lattices stacked one on the other, and having different porosity, allow different permeation kinetics of the analytes. ${ }^{36}$ This mechanism offers unique responses to pure analytes, which are obtained by a simple reflectance or transmittance measurement collected at a determined exposure time. In our case, thanks to the strong optical response typical of polymer DBR, this mechanism allows to recognize the analyte by simple naked eye investigation (Figure 4), offering the simplest selective signal transduction reported so far. In principle, the different affinity and diffusion kinetics of the analytes within the phase-changing PPO layers might also allow to identify a single vapor analyte within a complex mixture of vapors using a proper library of dynamic optical responses, but the analysis of mixture is still an open issue in the field of chromatic sensors based on DBRs

All-polymer DBRs based on phase-change active layers, such as those demonstrated in this work, can indeed pave the way for new generation colorimetric sensors with broad selectivity, that do not require any complex instrumentation, and can be detected even by the naked eyes. Such sensors would enable extensive and constant monitoring of VOCs pollution in offices and households directly by the end users.

\section{CONCLUSIONS}

We have demonstrated a proof-of-concept all-polymer DBR sensor able to distinguishing benzene, 1,2-dichlorobenzene, carbon tetrachloride and toluene via colorimetric detection. The phase transition of amorphous PPO thin films into semicrystalline nanoporous phases induced by the absorption of VOC vapors allows DBR sensors with label-free selectivity. During exposure to the different VOCs, the DBRs show a very dissimilar optical behavior, also detectable by naked eye. Notwithstanding the lack of reversibility of the detection system, the low cost materials and fabrication procedures might make disposable device viable from the economic point of view. Moreover, the visual colorimetric response of the sensor, which does not require any signal transduction, could potentially make these systems effective safety devices suitable for untrained end-users for monitoring of air quality and of VOCs leakages, also allowing constant and extensive pollution monitoring in industrial and urban areas.

\section{ASSOCIATED CONTENT}

\section{Supporting Information}

The Supporting Information is available free of charge on the ACS Publications website at DOI: 10.1021/acsami.6b10809.

Schematic of transflectance probe, IRRAS spectrum of a PPO thin film exposed to toluene vapors, transflectance spectra and detailed dynamic contour plot of a PPO-CA DBR during exposure to benzene, 1,2-dichlorobenzene, carbon tetrachloride, and toluene, reflectance spectra of a PPO-CA DBR having different top layers, contour plots of the DBR transflectance spectra upon $25 \mathrm{~min}$ of exposure for benzene, 1,2-dichlorobenzene, carbon tetrachloride, and toluene, and benzene sorption/ desorption kinetics transflectance spectra for a PPO-CA DBR (PDF)

\section{AUTHOR INFORMATION}

\section{Corresponding Authors}

*E-mail: paola.lova@edu.unige.it.

*E-mail: davide.comoretto@unige.it.

\section{Author Contributions}

P.L., D.C., P.R., and G.G. conceived the overall project and designed the experiments. C.B. and P.L. worked on the DBRs fabrications and sensing measurements. P.G. analyzed the literature and compared the sensor characteristics. M.P. and M.I. performed the ellipsometric measurements and their analysis. P.R. performed IRRAS experiments. Data were analyzed and modeled by P.L. and D.C. G.G. coordinated the activity on PPO. C.S. coordinated the activity on photonics in Singapore. D.C. coordinated sensor fabrication and optical characterization activities. The manuscript was written through contributions of all authors. All authors have given approval to the final version of the manuscript.

\section{Notes}

The authors declare no competing financial interest.

\section{ACKNOWLEDGMENTS}

Work in Genova and Salerno was funded by the Italian Ministry of University, Research and Instruction through the "Progetti di Ricerca di Rilevante Interesse Nazionale 2010-2011” Program (Materiali Polimerici Nanostrutturati con strutture molecolari e crystalline mirate, per tecnologie avanzate e per l'ambiente, 2010XLLNM3). Work in Genova is also supported by the European Union's Horizon 2020 research and innovation program under the Marie Sklodowska-Curie grant agreement No 643238. Research in NTU was partly supported by the Singapore Ministry of Education (grants MOE2011-T3-1-005 and MOE2013-T2-1-044). We thank Dr. Graziella Ianniello of University of Salerno for the experimental support.

\section{ABBREVIATIONS}

BEN, benzene; CA, cellulose acetate; CIA, color imagery analyses; CTC, carbon tetrachloride; DBR, distributed Bragg reflector; EG, ethylene glycol; IRRAS, infrared reflection absorption spectroscopy; MVA, multivariate analysis; MOF, metal-organic framework; o-DCB, 1,2-dichlorobenzene; PBG, photonic band gap; PEGMA, poly(ethylene glycol) methacrylate; PMMA, poly(methyl 2-methylpropenoate); PPO, poly( $p$ phenylene oxide); PTFE, poly(1,1,2,2-tetrafluoroethylene); R/ $\mathrm{T}$, reflectance or transmittance spectroscopy; TOL, toluene; VOC, volatile organic compound 


\section{REFERENCES}

(1) Guo, H.; Lee, S. C.; Chan, L. Y.; Li, W. M. Risk Assessment of Exposure to Volatile Organic Compounds in Different Indoor Environments. Environ. Res. 2004, 94, 57-66.

(2) Liu, X.; Cheng, S.; Liu, H.; Hu, S.; Zhang, D.; Ning, H. A Survey on Gas Sensing Technology. Sensors 2012, 12, 9635-9665.

(3) Koziel, J. A.; Pawliszyn, J. Air Sampling and Analysis of Volatile Organic Compounds with Solid Phase Microextraction. J. Air Waste Manage. Assoc. 2001, 51, 173-184.

(4) Ochiai, N.; Daishima, S.; Cardin, D. B. Long-Term Measurement of Volatile Organic Compounds in Ambient Air by Canister-based One-Week Sampling Method. J. Environ. Monit. 2003, 5, 997-1003.

(5) Pavia, D. L. Introduction to Organic Laboratory Techniques: A Small Scale Approach, Vol. 1, 1021, 2nd ed.; Thomson Brooks/Cole, Belmont, USA, 2005; pp 837-964.

(6) Descalzo, A. B.; Dolores Marcos, M.; Monte, C.; MartínezMáñez, R.; Rurack, K. Mesoporous Silica Materials with Covalently Anchored Phenoxazinone Dyes as Fluorescent Hybrid Materials for Vapour Sensing. J. Mater. Chem. 2007, 17, 4716-4723.

(7) Sinibaldi, A.; Descrovi, E.; Giorgis, F.; Dominici, L.; Ballarini, M.; Mandracci, P.; Danz, N.; Michelotti, F. Hydrogenated Amorphous Silicon Nitride Photonic Crystals for Improved-Performance Surface Electromagnetic Wave Biosensors. Biomed. Opt. Express 2012, 3, 2405-2410.

(8) Muro, M. L.; Daws, C. A.; Castellano, F. N. Microarray Pattern Recognition Based on PtII Terpyridyl Chloride Complexes: Vapochromic and Vapoluminescent Response. Chem. Commun. 2008, 46, 6134-6136.

(9) Jing, L.; Jianhua, X.; Shuang, X. Volatile Organic Compound Colorimetric Array Based on Zinc Porphyrin and Metalloporphyrin Derivatives. Energy Procedia 2011, 12, 625-631.

(10) Wang, L.; Dong, H.; Li, Y.; Xue, C.; Sun, L.-D.; Yan, C.-H.; Li, Q. Reversible Near-Infrared Light Directed Reflection in a SelfOrganized Helical Superstructure Loaded with Upconversion Nanoparticles. J. Am. Chem. Soc. 2014, 136, 4480-4483.

(11) Wang, L.; Li, Q. Stimuli-Directing Self-organized 3D LiquidCrystalline Nanostructures: from Materials Design to Photonic Applications. Adv. Funct. Mater. 2016, 26, 10-28.

(12) Zheng, Z.-g.; Li, Y.; Bisoyi, H. K.; Wang, L.; Bunning, T. J.; Li, Q. Three-Dimensional Control of the Helical Axis of a Chiral Nematic Liquid Crystal by Light. Nature 2016, 531, 352-356.

(13) Bisoyi, H. K.; Li, Q. Light-Directing Chiral Liquid Crystal Nanostructures: From 1D to 3D. Acc. Chem. Res. 2014, 47, 31843195.

(14) Khan, M. R. R.; Kang, B.-H.; Yeom, S.-H.; Kwon, D.-H.; Kang, S.-W. Fiber-Optic Pulse Width Modulation Sensor for Low Concentration VOC Gas. Sens. Actuators, B 2013, 188, 689-696.

(15) Wang, X.; Sun, X.; Hu, P. A.; Zhang, J.; Wang, L.; Feng, W.; Lei, S.; Yang, B.; Cao, W. Colorimetric Sensor Based on Self-assembled Polydiacetylene/Graphene-Stacked Composite Film for Vapor-Phase Volatile Organic Compounds. Adv. Funct. Mater. 2013, 23, 60446050

(16) Diehl, K. L.; Anslyn, E. V. Array Sensing Using Optical Methods for Detection of Chemical and Biological Hazards. Chem. Soc. Rev. 2013, 42, 8596-8611.

(17) Fenzl, C.; Hirsch, T.; Wolfbeis, O. S. Photonic Crystals for Chemical Sensing and Biosensing. Angew. Chem., Int. Ed. 2014, 53, 3318-3335.

(18) Zhao, Y.; Zhang, Y.-N.; Wang, Q. Research Advances of Photonic Crystal Gas and Liquid Sensors. Sens. Actuators, B 2011, 160, 1288-1297.

(19) Wu, L.; He, J.; Shang, W.; Deng, T.; Gu, J.; Su, H.; Liu, Q.; Zhang, W.; Zhang, D. Optical Functional Materials Inspired by Biology. Adv. Opt. Mater. 2016, 4, 195-224.

(20) Lova, P.; Soci, C.Organic and Hybrid Photonic Crystals, Vol. 1, 493, 1st ed.; Springer: Cham, Switzerland, 2015; pp 187-212.

(21) Lova, P.; Manfredi, G.; Boarino, L.; Comite, A.; Laus, M.; Patrini, M.; Marabelli, F.; Soci, C.; Comoretto, D. Polymer Distributed Bragg Reflectors for Vapor Sensing. ACS Photonics 2015, 2, 537-543.
(22) Wang, L.; Li, Q.Organic and Hybrid Photonic Crystals, Vol. 1, 493, 1st ed.; Springer International Publishing: Cham, Switzerland, 2015; pp 393-430.

(23) Wu, Y.-N.; Li, F.; Zhu, W.; Cui, J.; Tao, C.-A.; Lin, C.; Hannam, P. M.; Li, G. Metal-Organic Frameworks with a Three-Dimensional Ordered Macroporous Structure: Dynamic Photonic Materials. Angew. Chem. 2011, 123, 12726-12730.

(24) Yang, H.; Jiang, P.; Jiang, B. Vapor Detection Enabled by SelfAssembled Colloidal Photonic Crystals. J. Colloid Interface Sci. 2012, 370, 11-18.

(25) Xie, Z.; Cao, K.; Zhao, Y.; Bai, L.; Gu, H.; Xu, H.; Gu, Z. Z. An Optical Nose Chip Based on Mesoporous Colloidal Photonic Crystal Beads. Adv. Mater. 2014, 26, 2413-2418.

(26) Bai, L.; Xie, Z.; Cao, K.; Zhao, Y.; Xu, H.; Zhu, C.; Mu, Z.; Zhong, Q.; Gu, Z. Hybrid Mesoporous Colloid Photonic Crystal Array for High Performance Vapor Sensing. Nanoscale 2014, 6, 5680-5685.

(27) Zhang, Y.; Qiu, J.; Gao, M.; Li, P.; Gao, L.; Heng, L.; Tang, B. Z.; Jiang, L. A Visual Film Sensor Based on Silole-Infiltrated $\mathrm{SiO}_{2}$ Inverse Opal Photonic Crystal for Detecting Organic Vapors. J. Mater. Chem. C 2014, 2, 8865-8872.

(28) Wang, F.; Zhu, Z.; Xue, M.; Xue, F.; Wang, Q.; Meng, Z.; Lu, W.; Chen, W.; Qi, F.; Yan, Z. Cellulose Photonic Crystal Film Sensor for Alcohols. Sens. Actuators, B 2015, 220, 222-226.

(29) Ranft, A.; Niekiel, F.; Pavlichenko, I.; Stock, N.; Lotsch, B. V. Tandem MOF-Based Photonic Crystals For Enhanced AnalyteSpecific Optical Detection. Chem. Mater. 2015, 27, 1961-1970.

(30) Zhang, Y.; Fu, Q.; Ge, J. Photonic Sensing of Organic Solvents Through Geometric Study of Dynamic Reflection Spectrum. Nat. Commun. 2015, 6, 7510 .

(31) Zhang, Y.; Mu, L.; Zhou, R.; Li, P.; Liu, J.; Gao, L.; Heng, L.; Jiang, L. Fluoral-P Infiltrated $\mathrm{SiO}_{2}$ Inverse Opal Photonic Crystals as Fluorescent Film Sensors for Detecting Formaldehyde Vapor. J. Mater. Chem. C 2016, 4, 9841.

(32) Choi, S. Y.; Mamak, M.; von Freymann, G.; Chopra, N.; Ozin, G. A. Mesoporous Bragg Stack Color Tunable Sensors. Nano Lett. 2006, 6, 2456-2461.

(33) Ruminski, A. M.; King, B. H.; Salonen, J.; Snyder, J. L.; Sailor, M. J. Porous Silicon-Based Optical Microsensors for Volatile Organic Analytes: Effect of Surface Chemistry on Stability and Specificity. Adv. Funct. Mater. 2010, 20, 2874-2883.

(34) King, B. H.; Wong, T.; Sailor, M. J. Detection of Pure Chemical Vapors in a Thermally Cycled Porous Silica Photonic Crystal. Langmuir 2011, 27, 8576-8585.

(35) Dou, Y.; Han, J.; Wang, T.; Wei, M.; Evans, D. G.; Duan, X. Fabrication of $\mathrm{MMO}^{-\mathrm{TiO}_{2}}$ One-Dimensional Photonic Crystal and its Application as a Colorimetric Sensor. J. Mater. Chem. 2012, 22, 14001-14007.

(36) Kelly, T. L.; Garcia Sega, A.; Sailor, M. J. Identification and Quantification of Organic Vapors by Time-Resolved Diffusion in Stacked Mesoporous Photonic Crystals. Nano Lett. 2011, 11, 31693173.

(37) Lazarova, K.; Awala, H.; Thomas, S.; Vasileva, M.; Mintova, S.; Babeva, T. Vapor Responsive One-Dimensional Photonic Crystals from Zeolite Nanoparticles and Metal Oxide Films for Optical Sensing. Sensors 2014, 14, 12207-12218.

(38) Cui, C.; Liu, Y.; Xu, H.; Li, S.; Zhang, W.; Cui, P.; Huo, F. SelfAssembled Metal-Organic Frameworks Crystals for Chemical Vapor Sensing. Small 2014, 10, 3672-3676.

(39) Exner, A. T.; Pavlichenko, I.; Baierl, D.; Schmidt, M.; Derondeau, G.; Lotsch, B. V.; Lugli, P.; Scarpa, G. A Step Towards the Electrophotonic Nose: Integrating 1D Photonic Crystals with Organic Light-emitting Diodes and Photodetectors. Laser Photon. Rev. 2014, 8, 726-733.

(40) Ranft, A.; Pavlichenko, I.; Szendrei, K.; Zehetmaier, P. M.; Hu, Y.; von Mankowski, A.; Lotsch, B. V. 1D Photonic Defect Structures Based on Colloidal Porous Frameworks: Reverse Pore Engineering and Vapor Sorption. Microporous Mesoporous Mater. 2015, 216, 216224. 
(41) Lazarova, K.; Georgiev, R.; Vasileva, M.; Georgieva, B.; Spassova, M.; Malinowski, N.; Babeva, T. One-Dimensional PMMA $-\mathrm{V}_{2} \mathrm{O}_{5}$ Photonic Crystals Used as Color Indicators of Chloroform Vapors. Opt. Quantum Electron. 2016, 48, 310-317.

(42) Bonifacio, L. D.; Puzzo, D. P.; Breslav, S.; Willey, B. M.; McGeer, A.; Ozin, G. A. Towards the Photonic Nose: a Novel Platform for Molecule and Bacteria Identification. Adv. Mater. 2010, 22, 1351-1354.

(43) Hinterholzinger, F. M.; Ranft, A.; Feckl, J. M.; Ruhle, B.; Bein, T.; Lotsch, B. V. One-Dimensional Metal-Organic Framework Photonic Crystals Used as Platforms for Vapor Sorption. J. Mater. Chem. 2012, 22, 10356-10362.

(44) Bonifacio, L. D.; Ozin, G. A.; Arsenault, A. C. Photonic NoseSensor Platform for Water and Food Quality Control. Small 2011, 7, $3153-3157$.

(45) Tavakkoli K. G., A.; Nicaise, S. M.; Gadelrab, K. R.; AlexanderKatz, A.; Ross, C. A.; Berggren, K. K. Multilayer Block Copolymer Meshes by Orthogonal Self-Assembly. Nat. Commun. 2016, 7, 1051810527.

(46) Russo, M.; Campoy-Quiles, M.; Lacharmoise, P.; Ferenczi, T. A. M.; Garriga, M.; Caseri, W. R.; Stingelin, N. One-Pot Synthesis of Polymer/Inorganic Hybrids: Toward Readily Accessible, Low-loss, and Highly Tunable Refractive Index Materials and Patterns. J. Polym. Sci., Part B: Polym. Phys. 2012, 50, 65-74.

(47) Scotognella, F.; Varo, S.; Criante, L.; Gazzo, S.; Manfredi, G.; Knarr, R. J., III; Comoretto, D.Organic and Hybrid Photonic Crystals, Vol. 1, 493, 1st ed.; Springer International Publishing: Cham, Switzerland, 2015; pp 77-101.

(48) Fornasari, L.; Floris, F.; Patrini, M.; Comoretto, D.; Marabelli, F. Demonstration of Fluorescence Enhancement via Bloch Surface Waves in All-Polymer Multilayer Structures. Phys. Chem. Chem. Phys. 2016, 18, 14086-14093.

(49) Knarr, R. J., III; Manfredi, G.; Martinelli, E.; Pannocchia, M.; Repetto, D.; Mennucci, C.; Solano, I.; Canepa, M.; Buatier de Mongeot, F.; Galli, G.; Comoretto, D. In-Plane Anisotropic Photoresponse in All-Polymer Planar Microcavities. Polymer 2016, 84, 383390.

(50) Gazzo, S.; Manfredi, G.; Pötzsch, R.; Wei, Q.; Alloisio, M.; Voit, B.; Comoretto, D. High Refractive Index Hyperbranched Polyvinylsulfides For Planar One-Dimensional All-Polymer Photonic Crystals. J. Polym. Sci., Part B: Polym. Phys. 2016, 54, 73-80.

(51) Manfredi, G.; Mayrhofer, C.; Kothleitner, G.; Schennach, R.; Comoretto, D. Cellulose Ternary Photonic Crystal Created by Solution Processing. Cellulose 2016, 23, 2853-2862.

(52) Cavallo, D.; Goossens, H.; Meijer, H. E. H.Organic and Hybrid Photonic Crystals, Vol. 1, 493, 1st ed.; Springer International Publishing: Cham, Switzerland, 2015; pp 145-166.

(53) Lim, H. S.; Lee, J.-H.; Walish, J. J.; Thomas, E. L. Dynamic Swelling of Tunable Full-Color Block Copolymer Photonic Gels via Counterion Exchange. ACS Nano 2012, 6, 8933-8939.

(54) Convertino, A.; Capobianchi, A.; Valentini, A.; Cirillo, E. N. M. A New Approach to Organic Solvent Detection: High-Reflectivity Bragg Reflectors Based on a Gold Nanoparticle/Teflon-like Composite Material. Adv. Mater. 2003, 15, 1103-1105.

(55) Mönch, W.; Dehnert, J.; Prucker, O.; Rühe, J.; Zappe, H. Tunable Bragg Filters Based on Polymer Swelling. Appl. Opt. 2006, 45, 4284-4290.

(56) Convertino, A.; Capobianchi, A.; Valentini, A.; Cirillo, E. N. M. High Reflectivity Bragg Reflectors Based on a Gold Nanoparticle/ Teflon-like Composite Material as a New Approach to Organic Solvent Detection. Sens. Actuators, B 2004, 100, 212-215.

(57) Lova, P.; Manfredi, G.; Boarino, L.; Laus, M.; Urbinati, G.; Losco, T.; Marabelli, F.; Caratto, V.; Ferretti, M.; Castellano, M.; Soci, C.; Comoretto, D. Hybrid ZnO:Polystyrene Nanocomposite for AllPolymer Photonic Crystals. Phys. Status Solidi C 2015, 12, 158-162.

(58) Tarallo, O.; Petraccone, V.; Daniel, C.; Fasano, G.; Rizzo, P.; Guerra, G. A Chiral Co-Crystalline Form of Poly(2,6-Dimethyl-1,4Phenylene)oxide (PPO). J. Mater. Chem. 2012, 22, 11672-11680.
(59) Rizzo, P.; Ianniello, G.; Longo, S.; Guerra, G. Uniplanar Orientations and Guest Exchange in PPO Cocrystalline Films. Macromolecules 2013, 46, 3995-4001.

(60) Nakashima, K.; Ren, Y.; Nishioka, T.; Tsubahara, N.; Noda, I.; Ozaki, Y. Two-Dimensional Infrared Correlation Spectroscopy Studies of Polymer Blends: Conformational Changes and Specific Interactions in Blends of Atactic Polystyrene and Poly(2,6-Dimethyl-1,4-Phenylene Ether). J. Phys. Chem. B 1999, 103, 6704-6712.

(61) Bruggeman, D. A. G. Berechnung Verschiedener Physikalischer Konstanten von Heterogenen Substanzen. I. Dielektrizitätskonstanten und Leitfähigkeiten der Mischkörper aus Isotropen Substanzen. Ann. Phys. 1935, 416, 636-664.

(62) Perry, R. H.; Green, D. W.Perry's Chemical Engineers' Handbook, Vol. 1, 2704, 8th ed.; McGraw-Hill Professional: New York, USA, 1999; pp 2/48-2/89.

(63) Benedetti, E.; Moscatelli, D.; Vergamini, P. Intermolecular Interactions in Poly(2,6-dimethyl-1,4-phenylene oxide)/Poly(styrene) Blends from the Study of FT-IR Spectra at Various Temperatures. Macromol. Chem. Phys. 2002, 203, 1497-1500.

(64) Galizia, M.; Daniel, C.; Fasano, G.; Guerra, G.; Mensitieri, G. Gas Sorption and Diffusion in Amorphous and Semicrystalline Nanoporous Poly(2,6-dimethyl-1,4-phenylene)oxide. Macromolecules 2012, 45, 3604-3615.

(65) Daniel, C.; Longo, S.; Fasano, G.; Vitillo, J. G.; Guerra, G. Nanoporous Crystalline Phases of Poly(2,6-dimethyl-1,4-phenylene)oxide. Chem. Mater. 2011, 23, 3195-3200.

(66) Gehr, R. J.; Boyd, R. W. Optical Properties of Nanostructured Optical Materials. Chem. Mater. 1996, 8, 1807-1819.

(67) Potyrailo, R. A.; Bonam, R. K.; Hartley, J. G.; Starkey, T. A.; Vukusic, P.; Vasudev, M.; Bunning, T.; Naik, R. R.; Tang, Z.; Palacios, M. A.; Larsen, M.; Le Tarte, L. A.; Grande, J. C.; Zhong, S.; Deng, T. Towards Outperforming Conventional Sensor Arrays with Fabricated Individual Photonic Vapour Sensors Inspired by Morpho Butterflies. Nat. Commun. 2015, 6, 7959-7912.

(68) King, B. H.; Ruminski, A. M.; Snyder, J. L.; Sailor, M. J. OpticalFiber-Mounted Porous Silicon Photonic Crystals for Sensing Organic Vapor Breakthrough in Activated Carbon. Adv. Mater. 2007, 19, $4530-4534$.

(69) Colodrero, S.; Ocaña, M.; González-Elipe, A. R.; Míguez, H. Response of Nanoparticle-Based One-Dimensional Photonic Crystals to Ambient Vapor Pressure. Langmuir 2008, 24, 9135-9139.

(70) Hinterholzinger, F. M.; Ranft, A.; Feckl, J. M.; Ruhle, B.; Bein, T.; Lotsch, B. V. One-Dimensional Metal-Organic Framework Photonic Crystals Used as Platforms for Vapor Sorption. J. Mater. Chem. 2012, 22, 10356-10362. 